Orbis Tertius, vol. XXII, nº 25, e034, junio 2017. ISSN 1851-7811

Universidad Nacional de La Plata

Facultad de Humanidades y Ciencias de la Educación

Centro de Estudios de Teoría y Crítica Literaria

\title{
Los límites de la ausencia. Un ensayo sobre historia de las ideas: José Aricó, Leopoldo Zea y Carlos Real de Azúa
}

\section{Ximena Espeche * \\ * Universidad de Buenos Aires- Centro de Historia Intelectual-Universidad Nacional de Quilmes, Argentina}

\section{RESUMEN}

Propongo leer "Marx y América Latina" de José Aricó como un trabajo que discute los presupuestos de la historia de las ideas identificados con la producción de Leopoldo Zea en un sentido que lo vincula fuertemente con otro autor, Carlos Real de Azúa: las obsesiones, los límites y los alcances de una posible "historia esotérica" o "investigación filosófica”.

Carlos Real de Azúa

historia de las ideas

\section{KEYWORDS}

Latin-america

José Aricó

Leopoldo Zea

Carlos Real de Azúa

History of ideas

\section{ABSTRACT}

I propose reading José Aricó's "Marx y América Latina” as a work in which the author discusses Leopoldo Zea's proposals to study the history of ideas in such a way that it also relates to Carlos Real de Azúa's approaches: the obsessions and terms of a possible "esoteric history" or a "philosophical research".

Cita sugerida: Espeche, X. (2017). Los límites de la ausencia. Un ensayo sobre historia de las ideas: José Aricó, Leopoldo Zea y Carlos Real de Azúa. Orbis Tertius, 22(25), e034. https://doi.org/10.24215/18517811e034 


\section{Introducción}

El argentino José Aricó (1931-1991), exilado en México entre 1976 y 1982, publicó el libro Marx y América Latina en 1980 en Perú, y dos años después en México. ${ }^{1}$ La publicación del libro puede ser leída en el marco de los análisis y reflexiones que Aricó ya venía haciendo vinculados a la recepción, y el "desencuentro”, del socialismo en América Latina; y, sobre todo, puede ser comprendido en concordancia con una trama más amplia de discusiones llevadas a cabo en dicho país por exilados argentinos y de otros países latinoamericanos acerca de la derrota de la perspectiva revolucionaria, el rol de las organizaciones armadas y de los intelectuales (Portantiero 1999; Crespo 2009: 9-28; Yankelevich 2010). El libro de Aricó se propuso, entre otras cosas, explicar las razones de ese "desencuentro" entre socialismo y América Latina, y seguir de cerca una ausencia —o "soslayamiento"- y un malentendido. $\underline{\underline{2}}$ Esto es: por un lado explicar la ausencia notoria de reflexiones de Carlos Marx sobre América Latina, o las reflexiones que lo harían insistir en la incapacidad de estos pueblos para tener una "historia" (frente a las posibilidades de las experiencias rusa e india). Aricó siguió de cerca la producción de Marx vinculada a la colonización y a la diferenciación entre Occidente/Oriente, y se detuvo en el escrito de este último sobre Bolívar. Por el otro, criticó en su análisis la suerte de malentendidos o de lecturas sesgadas sobre las reflexiones de Marx que sólo podían ver allí los límites del autor valorándolos como eurocentrismo — de matriz hegeliana, y vinculado a la jerarquización del lugar de la historia de América Latina en Occidente.

En general, las lecturas sobre este libro están centradas en sumarlo a una serie vinculante con otras producciones de Aricó y los desplazamientos relativos a su trayectoria político-intelectual. Para Juan Carlos Portantiero, amigo y colega de Aricó con quien compartió el exilio, la estadía mexicana de este último habría significado su "descubrimiento de América Latina”, "un punto de viraje” y "un corte importantísimo en la definición de su trayectoria intelectual”:

Así como maduró su propia visión del socialismo, se perfiló también su vocación de historiador de las ideas, y, sin perder sus obsesiones generosas de organizador y difusor de la cultura, pudo dar cauce, en el acicateador ambiente mexicano, a una tarea de investigador para la cual, fuera de las aulas convencionales de la universidad, se había preparado desde hacía mucho tiempo (1999: 7).

Como señala Portantiero, el exilio mexicano implicó un cambio en el pensamiento de Aricó así como también un nuevo modo de posicionarse en relación con su producción y práctica como intelectual. El libro Marx y América Latina puede convertirse, entonces, también en un excelente ángulo de toma para revisar hasta qué punto la apuesta analítica de Aricó tuvo, en esta vocación de historiador de las ideas, un nudo fortísimo que necesariamente tenía que posicionarse en un ambiente señoreado por el mexicano Leopoldo Zea, al que nunca nombra en su libro. De lo que trato aquí es de capturar una apuesta como la de Aricó respecto de los modos de leer y entonces de apuesta por la capacidad analítica y de intervención políticocultural de la historia de las ideas. Y, para seguir esta trama, vale la pena revisar qué otros exponentes de la historia de las ideas en América Latina discutieron de manera explícita las opciones analíticas de Zea, como fue el caso del uruguayo Carlos Real de Azúa. $\underline{3}$

Aunque mi análisis esté centrado en estas formas de leer, es necesario poner en relación - $\mathrm{y}$ en un mismo mapa - a tres autores que no han sido vinculados en estos términos, según el estado de un campo en un momento específico: el del ambiente mexicano, receptor de exilados de todo el continente; la crisis del marxismo y sus reverberaciones latinoamericanas; y la reflexión sobre la derrota de las izquierdas y de la perspectiva revolucionaria. 4

\section{América Latina y marxismo}

En México, muchos/as exilados/as argentinos/as se nuclearon en torno a diversas asociaciones civiles y 
políticas cuyos objetivos fueron, entre otros, la denuncia de los crímenes de la dictadura, la búsqueda de consensos para lograr apoyo internacional contra el accionar de los militares y así generar presión política a los efectos de que la dictadura pusiera fin a esos crímenes y esclareciese la situación de los desaparecidos (Farías 2013). La revista Controversia para un análisis de la realidad Argentina (1979-1981) de la que Aricó fue uno de sus principales miembros estaba vinculada a una de esas asociaciones, la Comisión Argentina de Solidaridad (CAS), creada por un grupo de exiliados que defendió la idea de "conformar un ámbito donde pudieran tener cabida otras alternativas políticas” que las lideradas por el Comité de Solidaridad con el Pueblo Argentino (COSPA), vinculada a Montoneros (Yankelevich 2010: 138). $\underline{5}$

Además, Aricó fue profesor del Colegio de México — donde dictó el seminario "Introducción a Marx" en 1976—, y de la Universidad Autónoma de Puebla (UAP) —en cuyo Centro de Estudios Contemporáneos del Instituto de Ciencias discutió avances del libro (Aricó 2009 [1982]: 77) — y su trabajo principal fue en la editorial Siglo XXI — que había sido una empresa cultural de referencia en la modernización de las ciencias sociales de América Latina y en cuya filial argentina Aricó había trabajado de 1971 a 1976. $\underline{6}$ En síntesis, estaba inmerso en el campo cultural mexicano, aunque no discutiera activamente sobre México (dado que en tanto que exilado lo tenía prohibido) sino sobre América Latina y Argentina en particular en el contexto de la derrota de la perspectiva revolucionaria, la égida de las dictaduras en la región y la avanzada feroz contra los derechos humanos.

Las caracterizaciones más usuales de la figura de Aricó recalcan sus cuestionamientos a los itinerarios de un marxismo ortodoxo utilizado por un partido comunista del mismo tenor — partido del que fue expulsado junto con otros jóvenes argentinos de su generación en 1963 bajo la sospecha de fraccionalistas. También es reconocido por su exploración crítica — y distanciada — relativa a las interpretaciones sobre la especificidad latinoamericana que Marx habría malentendido, del que su libro Marx y América Latina es un claro exponente. De hecho, un trabajo como su análisis de la ausencia o malentendido de América Latina en Marx implicó retomar sus obsesiones anteriores y prácticas de un traductor y gestor cultural. Hago referencia aquí, entre otras cosas, a su trabajo como coeditor de la ya mítica revista Pasado y Presente —que fue financiada en dos números por el Partido Comunista Argentino (Córdoba, 1963-1965) y a cuyos “compañeros” está dedicado Marx y América Latina-, de los Cuadernos de Pasado y Presente que eran monográficos de intervención político-cultural (Buenos Aires, 1971-1973); y, además de su participación en Controversia, a sus estudios sobre Antonio Gramsci y José Carlos Mariátegui y, especialmente, a su rol como director de la colección Biblioteca del pensamiento socialista de la editorial mexicana Siglo XXI. $\underline{7}$

Pero me interesa aquí poner el foco en otro lado, y este es el de pensar la figura de Aricó también como historiador de las ideas, que propuso/disputó acerca de las formulaciones teórico-metodológicas de esa misma disciplina. Y esto puede verse a trasluz: justamente en su intento por entender y auscultar el marxismo distanciándose de otros acercamientos tanto teórico como militantes (desde los revisionismos y la izquierda nacional hasta el comunismo) que insistían en afirmar la existencia de una producción marxiana sin fisuras. Guillermo Ricca lo dice en estos términos: el libro de Aricó sobre Marx y América Latina es tanto un trabajo de historia intelectual como un ensayo que muestra la productividad de pensar a Marx como un autor menos “sistemático” que lo que en general se ha supuesto (Ricca 2013: 78). Diría, extremando la asunción de Ricca, que justamente "desistematizar" el pensamiento marxiano implicaba una apuesta epistemológica distanciada de la tradicional historia de las ideas latinoamericana de la que Zea era un referente indiscutible.

Como analiza Elías Palti, Zea había realizado un movimiento crítico respecto de la historia de las ideas hegemónica en los años cuarenta liderada por el estadounidense Arthur Lovejoy, sin por ello desarmar sus fundamentos. Para Lovejoy, las ideas funcionan como núcleo de sentido en la producción cultural, porque supone que el fundamento de la existencia y producción de las ideas es antropológico. Y, como además 
tienen la capacidad de migrar, precisan de una disciplina que pueda dar cuenta de esas migraciones de una cultura, época o disciplina particular a otra. Zea matizó la asunción de las "ideas" sólo como propias de “Occidente” y buscó entonces los casos particulares, esto es, la caracterización de un positivismo específico como el de México, aunque no enjuició la existencia y continuidad de ese núcleo: lo que definía el positivismo in toto asumiendo así un estudio de sus derivados — como el mexicano—, cuestión que entonces afirmaba la existencia de modelos (Palti 2007: 272). $\stackrel{8}{ }$ Como veremos, para Zea de lo que se trataba era de afirmar aquellas cualidades centrales que hacían la diferencia per se de la producción latinoamericana respecto de otras en la órbita de Occidente. Por el contrario, Aricó desestimó en su Marx y América Latina la continuidad sin fisuras de una idea cuyo núcleo se pareciera siempre a sí mismo, y para ello historizó el carácter concreto de la producción y reflexión marxianas. Y, como veremos, dudó además de la continuidad o sistematicidad de la idea misma de América Latina (en particular siguiendo el modo en que se había articulado con el sintagma "latinidad”). Esa idea de “América Latina” es la que, como comunidad, Zea fue construyendo a lo largo de sus escritos: la idea de comunidad sostenía la chance del futuro más allá de la crisis de la modernidad; esta opción estaba ligada a la valorización de lo latino, caracterizado en un ensayo que se volvería clásico gracias a las prácticas lectoras y militantes de los reformismos universitarios latinoamericanos: el Ariel del uruguayo José E. Rodó. Allí, el componente "latino" implicaba una espiritualidad desinteresada, capaz de oponerse al avance masificador del materialismo sajón. Y ambas cuestiones serían a su vez foco de una denuncia antiimperialista propiciada por esos reformismos a la que Zea llegaría promediando los años sesenta. ${ }^{9}$ Así, Aricó se distanció tomando posición críticamente respecto de la sustancialidad de las ideas (y consecuentemente sobre el modo de abordar los textos) y sobre la sustancialidad de América Latina.

\section{Traducir “América Latina”}

Leopoldo Zea era para 1980 un prohombre del pensamiento mexicano y de toda América Latina, y el tipo de asunciones que manejaba eran ya a esa altura un sentido común vinculado a la factura de la historia de las ideas subcontinental. Zea se había dedicado a la filosofía de la historia, a revisar cuánto del positivismo mexicano tenía qué conjuntos de particularidades de ese país que lo hacían muy específico; además estaba enfrascado en explicar la capacidad en América Latina de producir una filosofía "sin más", objeto de una discusión muy conocida con Augusto Salazar Bondy en 1968, quien observaba justamente lo contrario: América Latina y su falta de originalidad, su ser como si dijéramos de "segundo grado" en cualquier actividad intelectual, especialmente una como la del quehacer filosófico. Zea, recordemos, también era un incansable articulador de "equipos a distancia", quien pensaba y coordinaba posibles integraciones latinoamericanas a la luz de esa filosofía instalada en las "circunstancias", en el sentido orteguiano del término. Y que, para la fecha en que Aricó estaba exilado en México, había tenido varios cargos en instituciones educativas mexicanas (sin ir más lejos, fue director de la Facultad de Filosofía y Letras de la UNAM (1966-1971), en 1966 convirtió el Seminario de Historia de las Ideas — que había dirigido — en el Centro de Estudios Latinoamericanos y recibió entre otros premios el Premio Nacional de Ciencias y Artes en $1980 . \underline{10}$ En definitiva Zea, para la época en que Aricó se encontraba en México, trabajando en la editorial Siglo XXI, era un funcionario, y seguía siendo un latinoamericanista reconocido.

Sus intervenciones de los años setenta fueron "Latinoamérica Tercer Mundo" (1976), Dialéctica de la conciencia americana (1976) y Filosofía de la historia americana (1978). En todos los casos estaba decidido a rechazar la opción capitalista, buscando la apropiación de la palabra del dominador por parte del dominado — como Tercer Mundo o desarrollo—, el reconocimiento de la separación entre "dirigentes" (como colaboracionistas de ese mismo capitalismo en su fase imperialista) y "pueblo" y, sobre todo, la discusión sobre el carácter de la Historia y del ingreso de América Latina en ella (revisitando un ítem central en su 
producción como lo son sus lecturas del historicismo hegeliano). En 1980, publicó Simón Bolívar, integración en la libertad y en 1983 “Marx y Bolívar” en la revista Nueva Sociedad, artículo sobre el que volveré enseguida.

Con todo ello quiero dibujar un retrato sintético pero que viene bien para comprender esa suerte de diálogo de sordos que había entre las producciones editadas en el México de fines de los años setenta y comienzos de los años ochenta sobre quizá una de las cuestiones centrales que habían acechado los estudios de Zea y Aricó: esto es, esa afirmación sobre los "pueblos sin historia” que parecía caracterizar a los latinoamericanos según la perspectiva hegeliana que Marx utilizara para explicar en un retrato malogrado a Bolívar. Para Aricó, se trataba de que:

La singularidad latinoamericana no pudo ser comprendida por dicho movimiento [por Marx y el socialismo] no tanto por el "eurocentrismo" de éste, como por la singularidad de aquella. La condición ni periférica ni central de los estados-nación del continente; el hecho de haber sido el producto de un proceso al que gramscianamente podríamos definir como de revolución "pasiva”; el carácter esencialmente estatal de sus formaciones nacionales; el temprano aislamiento o destrucción de aquellos procesos teñidos de una fuerte presencia de la movilización de masas, fueron todos elementos que contribuyeron a hacer de América Latina un continente ajeno a la clásica dicotomía entre Europa o Asia que atraviesa la conciencia intelectual europea desde la Ilustración. Es por todo ello que resulta pobre, limitado y falso asignar el supuesto "eurocentrismo" marxiano al paradójico soslayamiento de la realidad latinoamericana. La presencia obnubilante de los fenómenos del populismo que caracterizan a la historia de nuestros países en el siglo XX llevó curiosamente a identificar eurocentrismo con resistencia a toda forma de bonapartismo, o de autoritarismo. El resultado fue una fragmentación cada vez más acentuada del pensamiento de izquierda, dividido entre una aceptación del autoritarismo como costo ineludible de todo proceso de democratización de las masas, y un liberalismo aristocratizante como único resguardo posible del proyecto de una sociedad futura, aún al precio de enajenarse el apoyo de las masas. Aceptar la calificación de "eurocéntrico" con que se pretende explicar la oclusión marxiana implica de hecho cuestionar el filón democrático, nacional y popular que constituye una parte inescindible del pensamiento de Marx (Aricó 2009 [1980]: 134-5)

Bajo la reflexión final que este fragmento ilustra, Aricó propuso explorar la manera en que la crítica acusatoria de Marx como eurocéntrico no quería ver, finalmente, lo que el marxismo tendría para analizar aquellos procesos nacional-populares que no podían explicarse sólo en términos de desviaciones demagógicas de la democracia. Aricó, además, historizó el marco de "latinidad” que América Latina tiene en su nombre: lo hizo buscando el carácter histórico-político de ese nombre en la invasión de Francia a México, luego continuó el análisis en el uso de las élites letradas de los jóvenes estados hispanoamericanos contra la herencia colonial y el "rechazo al expansionismo yanqui” (Aricó 1980: 111). Y especificó las variaciones sobre lo que el nombre designaba — “supeditación ideológico-cultural” a Francia— hasta la Primera Guerra Mundial para abrir, con la Rusia de 1917 "un nuevo proceso de búsqueda de su identidad que se expresa una vez más en la querella de las designaciones”. Así ingresó el “indoamericanismo” —y entonces aquí Aricó miraba ahora a José Carlos Mariátegui— bajo el que "la primera revista que intenta fundar la singularidad latinoamericana busca en la América "antigua” el título a través del cual aquella emerja como una nueva forma de ver a Europa y al mundo" (Aricó 2009 [1980]: 112). En un texto posterior, introducción a su estudio La hipótesis de Justo, Aricó lo explicaba sintéticamente ya en el subtítulo: “América Latina como una unidad problemática” (Aricó 1999: 11).11 En definitiva, diría que lo que hay es una discusión sobre los sentidos de América Latina, objeto tan en disputa como las palabras de Marx. 
El problema era, también, el de traducir América Latina, y por ello Aricó repuso una historia que intenta traducir la serie compleja — e históricamente situada - de interpretaciones que podría haber tenido en un Marx ese mismo peso de latinidad. Eran obsesiones de traductor, o para decirlo con Martín Cortés, "La traducción supone siempre un ejercicio de fino análisis de la configuración nacional específica y eso implica siempre un esfuerzo de lectura.” (Cortés 2010: 163). $\underline{12}$ Es cierto que el trabajo de Aricó como “traductor”, en el sentido literal de traducir obras como las de Gramsci o las Grundrisse de Marx al español, y en el sentido tal como lo maneja Cortés citado más arriba (el "ejercicio del fino análisis”) es anterior al que realiza en su exilio mexicano. Y que la referencia al Gramsci de la "traducibilidad de los lenguajes políticos" es posterior (si bien Robert Paris se había detenido en el famoso seminario sobre Mariátegui en Sinaloa en 1980): es en 1985 en el seminario internacional organizado en Ferrara, Italia, y luego su La cola del diablo. Itinerarios de Gramsci en América Latina, donde justamente Aricó recupera y amplía esa presentación de Ferrara (Aricó 1987). Diré entonces que la cuestión de la traducción — retomando la perspectiva gramsciana — es un modo que lee la relación entre contextos de enunciación, producción, recepción, etc. en términos políticos, como praxis. Ello implica un trabajo sobre los textos que explore las discontinuidades y los matices y, a la vez, los piense enmarcados en la efectividad de una palabra que buscaba convencer políticamente para una acción: la transformación social. Como dijo hace tiempo Jorge Panesi (1994) sobre la cultura letrada argentina y esa suerte de necesidad de traducción (en el sentido borgeano de que así se produce una cultura, un modo de vida, un pasado útil), Aricó se puso sobre los hombros la discusión con las prácticas culturales de un partido - como el comunista - o de otros análisis que consideraba rengos sobre el marxismo, y directamente también se puso al hombro la discusión contra las afirmaciones que regían un método que pareció asumirse como latinoamericanista. Y lo que estaba también ahí presente era un tiro por elevación: ¿qué quería decir, entonces, esa América Latina sobre la que Zea venía insistiendo?

\section{Confluencias heroicas}

Como mencioné, Zea había estudiado la recepción de "pensamientos” e "ideas” europeos en América Latina, como su clásico ensayo sobre el positivismo; y también se había dedicado a discutir el carácter del imperialismo y colonialismo en América Latina. Zea viajó por diversos países latinoamericanos entre 1945 y 1947, relacionándose con exponentes de una incipiente comunidad de historia de las ideas latinoamericana, en lo que Horacio Tarcus (2015) menciona como un "segundo hito" que tuvo como corolario el proyecto para la creación de un "Comité de historia de las ideas" en la Comisión de Historia del Instituto Panamericano de Geografía e Historia dependiente de la OEA (del que participaría, entre otros, un reconocido exponente de ese campo de investigaciones, el uruguayo Arturo Ardao). Todavía no había desarrollado en esa búsqueda de la historia de las ideas “americana” una impronta antiimperialista.

El "primer hito" de esa historia habría sido la fundación en Argentina y México, y de manera contemporánea, de la Cátedra de pensamiento Alejandro Korn en el Colegio Libre de Estudios Superiores por parte de Francisco Romero y del Seminario para el estudio del pensamiento en los países de lengua española en la Casa de España en México (que luego pasaría a convertirse en el Colegio de México), por el exilado español José Gaos respectivamente en 1940. Para Tarcus (2015), en 1978 comenzaría otro tramo, bajo la perspectiva de la historia intelectual —y a partir de una presentación de Juan Marichal en España de una crítica de la historia de las ideas de Arthur Lovejoy. $\frac{13}{13}$ Así, para la fecha en que Aricó publicó en México su trabajo, la historia de las ideas a la que Zea adscribía era objeto de cuestionamientos. Frente a ellos, Zea continuaba su prédica, pero actualizando sus objetos y referencias.

En 1983, la revista venezolana Nueva Sociedad publicó un dossier dedicado a Marx con motivo de los cien años de su muerte. Allí tanto Aricó como Zea presentaron sus trabajos. ${ }^{14}$ En la espacialidad de la revista, en la sincronía del papel, las visiones sobre Marx no pueden ser más divergentes, y diríamos, sordas entre sí. En 
"Visión de Marx sobre América Latina”, Zea nombró a Aricó después de la publicación de Marx y América Latina y al mismo tiempo que este publica en esa misma revista un artículo titulado igual que su libro de 1980. Pero la mención de Arico que hace Zea es sólo a modo de nota a pie. Ese gesto puede ser leído sin demasiada dificultad como la incorporación de una cita que revela el conocimiento de una serie de producciones específicas sobre un tema dado (recepción del marxismo). Y ello es aún más claro cuando al leer el texto de Zea éste insiste en aquello que el propio Aricó desestimaba con Marx y América Latina, y que repitió en la publicación de su texto en Nueva Sociedad. Es decir, para Aricó se trataba de arribar a una crítica de las conclusiones marxianas más allá de una suerte de comodidad analítica que el eurocentrismo vendría a resaltar. Por el contrario, Zea hizo caso omiso a esas evaluaciones y sólo veía en Marx el resultado de un pensamiento eurocéntrico, y allí la ignorancia de ese mismo pensamiento. Zea se detuvo en la categoría "hombres de su tiempo" (entonces en la "circunstancia”) por lo que Marx y Engels habrían tenido un límite para comprender las particularidades de Bolívar y de toda América Latina: su eurocentrismo. Refiriéndose a las fuentes o ejemplos que Aricó había rastreado para mentar una diferencia vinculada con esta noción (el problema era menos esa característica que explicar América Latina en términos de occidente/oriente), Zea insistió en leer allí una continuidad interpretativa que ligaba directamente a la filosofía de Hegel. Zea, por otra parte, quería hacer confluir a los dos personajes que darían cuenta del desencuentro, esto es, Marx y Bolívar:

Lo que ya destacaba el Che Guevara en 1960, se ha presentado en nuestros días en forma crítica entre varios marxistas latinoamericanos al recordarse, por un lado, el bicentenario del nacimiento de Simón Bolívar y, por el otro, el centenario de la muerte de Marx. Un problema que parece de lealtades. Lealtad como latinoamericano a la obra y trascendencia de Bolívar y, como marxista a la doctrina revolucionaria de éste. Lo cierto es que, cada uno en su campo, en el de la acción libertadora, y en el de la doctrina que ofrece instrumentos para ampliar esas acciones, siguen vigentes. Una vigencia que no debe ser vista como contradictoria (Zea 1983: 59)

Zea organizó una confluencia que, al mismo tiempo, definía otra: la del militar/revolucionario y la del teórico/militante cuya síntesis era el Che Guevara —al que Zea citó en su ensayo. Por esos años, la revista Controversia... intentaba revisar ciertos presupuestos en el análisis de la derrota de las organizaciones armadas revolucionarias en Argentina, y en una tesis polémica afirmó que estas habían sido derrotadas políticamente incluso antes que militarmente. A la luz de esa tesis, la afirmación de Zea se volvía problemática: insistir en la figura del intelectual revolucionario como confluencia entre el militar/revolucionario y teórico/militante era, así, un problema donde la voluntad no podía resolver las cuestiones que, estructurales e históricas, habían derrotado las potencias y actos de esa figura. Esto es, el planteo de Aricó se hacía cargo de dimensiones históricas evaluadas como las que habían llevado a la derrota, dimensiones que Zea no tomaba en cuenta apelando a la figura voluntarista por excelencia. $\frac{15}{15}$ Podemos pensar que visto bajo esa lupa, la discusión sobre cómo hacer historia de las ideas era para Aricó, singularmente, una apuesta concreta: buscar allí también la historia de cómo habían sido posibles lenguajes políticos nuevos, y que esa búsqueda constituyese al mismo tiempo la articulación entre teoría y práctica.

\section{Aires de familia}

En este punto, vale la pena traer a colación a otro autor, esta vez uruguayo quien — esta vez sí de forma explícita - definía de qué otro modo era posible y necesario hacer historia de las ideas. Hago referencia aquí al uruguayo Carlos Real de Azúa, porque diría que en esta presencia efectiva de la discusión con Zea me fue posible leer la ausencia de ese mismo autor en el trabajo de Aricó. Real de Azúa publicó Historia visible e historia esotérica en 1975, cuando la dictadura uruguaya tenía ya dos largos años de vida. Poco después lo retiró de circulación, y lo hizo porque (no ha sido confirmado pero es plausible) no podía discutir desde 
Uruguay sobre esos temas en ese momento. Se abría para Uruguay, se habían abierto para Chile, y lo harían poco después para Argentina tiempos duros y feroces. Real de Azúa era para muchos de su generación, conocida como la generación crítica o generación del ‘45, incluso como "generación de Marcha” (haciendo referencia al mítico semanario uruguayo) un personaje incómodo, heterodoxo, habitué lector de lo último en la producción intelectual internacional. Real de Azúa era abogado, crítico literario, introductor de los clásicos de la sociología y ciencia política estadounidense en Uruguay, y se volvería ya entrados los años ochenta en un referente en esas últimas dos disciplinas —en particular debido a la recepción de sus estudios sobre el poder y la institucionalidad de los partidos políticos en Uruguay. Un hombre que había apoyado a la falange y que publicó un libro para entender ese apoyo tan equívoco y errado; que cada vez más fue optando por la capacidad transformadora de un nacionalismo revolucionario al que le dedicó un volumen escrito al fragor de los discursos de Fidel Castro entre 1961 y 1963 y que estuvo inédito hasta entrados los años 90. $\underline{16}$

Real de Azúa insistía en que en historia de las ideas había que estar atentos a una clave interpretativa, pero también a un modo de auscultar las fuentes, interesada en lo que llamó la "condición-situación”. Era menos la atención en el "lastre”, la "culpa”, “conjura” o el "complot” de o sobre América Latina que ponderar cuánto de esas acusaciones y paranoias apuntaban a rasgos ineludibles en la historia del subcontinente como, por ejemplo, el peso del imperialismo. Se trataba de atender a la condición difusa de las ideas y las ideologías, a comprender igualmente lo que de arraigado ellas tenían en un momento particular. Bajo la dialéctica del palimpsesto, tendría en cuenta de qué forma cualquier "gran tema" — como el de modernización, por ejemplo — se hallaba inscrito sobre otro anterior sin borrarlo ni cancelarlo, como si se tratara de un juego de elementos latentes y manifiestos (Real de Azúa 1975: 12).

En parte estaba respondiendo a los parámetros que Leopoldo Zea desde México y, en su país, el también uruguayo Arturo Ardao, privilegiaban para ese quehacer historiográfico (Ardao fue una suerte de representante para el cono sur de esa historia de las ideas que Zea parecía liderar, y que en 1957 había fomentado la creación de un Centro de Historia de las Ideas en Uruguay). Porque de lo que se trataba era el interés de Real de Azúa en "ciertas configuraciones durables” y "no tanto en su curso histórico lineal”. Y "aun si de ideas e ideologías se trata me importan siempre más los supuestos de ellas que sus efectivizaciones, más las latentes y difusas que esas formuladas y explícitas que trabaja regularmente la ‘historia de las ideas' en América Latina”.

En una reseña del libro de Zea, América Latina en la historia, que había publicado con motivo de la salida del trabajo de Zea en 1958 y que decidió revisitar en Historia visible... en 1975, Real de Azúa criticaba a Zea uno de los puntos nodales que hacen a todo su andamiaje investigativo. $\frac{17}{}$ En el libro de Zea había una paradoja en el análisis: la de los occidentales modernos aliándose a los antioccidentales premodernos (Real de Azúa 1975: 59). Para el autor mexicano, Occidente funcionó como elemento modernizador, cuyos valores positivos eran los de la lucha por la dignidad y derechos del hombre y el progreso de la técnica para su beneficio y felicidad. Pero, a la vez, en la periferia lo hizo impidiendo la modernización al aliarse y utilizar las entidades adversas a esos principios constitutivos. De hecho, Occidente negaba así aquello que era positivamente universal y al hacerlo cortaba de cuajo su propio fundamento civilizatorio. El ejemplo más claro era el del imperialismo que era una máquina de impedir el desarrollo de la periferia. $\underline{18}$

En la comparación entre las dos Américas (sajona y la íbero-latina) Zea completaba una imagen dando sustento a esa historia en la que América Latina se inscribía: a diferencia de las evaluaciones que trababan el ingreso del subcontinente en la historia occidental porque consideran que lo que allí existía era solamente retardatario, Zea reconoció un valor específico en esa "peculiaridad ibérica", demostrando que esa diferencia era justamente lo que la hacía ingresar en la historia, y mejor aún, en un futuro redentor de la modernidad considerada en crisis. 
Para Real de Azúa, el libro de Zea era un intento de “filosofía de la historia de las ideas” erigido como si se tratara de una "filosofía de la historia a secas", que terminaba por ser esquemático, en parte por "cierto desdén por la particularidad” y una "abusiva simplificación de la multiplicidad de la historia”. Y en el caso de una filosofía de la historia de las ideas manejaba nociones ambiguas, "instrumentos conceptuales elevados a la univocidad gracias a la eliminación de su variado condicionamiento en el mundo real”. Así, Zea rotulaba, y al hacerlo hipostasiaba la realidad misma. Zea veía claramente una doble pertenencia en la “conciencia de la marginalidad" de América Latina y en "la paralela operancia mundial de este estado de espíritu” (la adhesión iberoamericana a los bienes de Occidente). Pero no había visto que lo moderno se había expandido a naciones diferentes entre sí, que los resabios no modernos no eran un lugar al que llegar sino también un lugar desde donde partir (religión, aristocracias tradicionales, vida corporativa, reflejos noeconómicos, etc.). Occidente en la consideración de Real de Azúa era una composición de naciones "en constante tensión y competencia” (1975: 54-55). La insistencia de Real de Azúa en el matiz expone también una crítica al modo en que Zea organizó una historia de las ideas: "Una pura dialéctica de ideas tiende a prescindir de su propio y variado condicionamiento" (1975: 61). En definitiva, por más que Zea insistiese de forma explícita en la condición de la "circunstancia" de las ideas, los sujetos y su tiempo o época, que las hacían posibles, retenía en su planteo una condición de a-historicidad notoria.

\section{Conclusiones}

Ese modo de trabajo criticado por Real de Azúa es también el modo de trabajo que Aricó rechaza. De hecho, este último había escrito en su prólogo a la edición de la correspondencia de Marx, Nicolai F. Anderson y Friedrich Engels —editada en Siglo XXI en 1981 y como parte de la Biblioteca del Pensamiento Socialista - que su estudio no era "una mera operación arqueológica y sin otra importancia que la de abonar ese campo neutro e indiferenciado de la historia de las ideas. Dicho de otro modo, sólo un intento postrero por salvar a toda costa a Marx del naufragio de la metafísica occidental y del marxismo en ella incluido” (Aricó 1981: XIV). Es que la cuestión estaba en la cualidad de eso "indiferenciado" y "neutro": si para Zea justamente el modo de la "circunstancia” arraigaba las investigaciones en un núcleo específico y, diría, cuasiesencial, era esa esencialización (¿idealismo?) que volvía el gesto de la particularización un gesto inocuo para la transformación concreta de interpretaciones que debían ser al mismo tiempo una formulación precisa de una praxis específica: la del cambio social. Diría más, la vocación de historiador de las ideas encontraba para Aricó un límite cuando el trabajo con las fuentes desconocía la historicidad de las lecturas, de las recepciones, de la disputa por la verba marxiana. Así, hizo del potencial crítico de la verba marxiana un modo también de auscultar esa misma verba. Quizá aquí podríamos revisar hasta qué punto la cuestión del límite abre a una figura que Verónica Gago ha llamado "investigación filosófica”: que trata de "indagar las voluntades que están detrás de cada construcción de conceptos que se identifican con el nombre de un autor pero que realmente obedecen a un problema que distribuye elementos y retaza fronteras" donde en el “zigzagueo” del pensamiento es posible encontrar "un modo de la escritura investigativa” (Gago 2012: 111).

Marx y América Latina pareciera tocarse con algunas de las formulaciones enunciadas por Real de Azúa. También podríamos pensar que estas últimas están dentro de esa "investigación filosófica”. Quiero decir: una lectura a contrapelo, sin solemnidades pero sí comprehensiva de la tragedia de la historia, que tratase de entender por qué quedaron asentadas ciertas formulaciones tomadas como verdades históricas. En esos términos, Aricó además aclaraba en su libro que:

Así como la historia de la iglesia no es idéntica a la historia del cristianismo ni la contiene in toto, la historia del marxismo desborda las vicisitudes de la vulgata y de sus “desviaciones”. Además de una historia esotérica como institución y como dogma, como hecho de ideas y de figuras intelectuales, es innegable que hay otra historia suya discontinua y descentrada, plena de morfologías ocultas, de 
sendas perdidas y de temporalidades diversas; una historia esotérica y pluralista en la que se expresa la multiplicidad de tentativas, de proyectos y de resultados de la lucha de las clases subalternas. Negada como reconstrucción ideal, cronológica y rectilínea de una ortodoxia — que no deja de ser tal por el hecho de instituirse a partir de ciertas corrientes o centros teóricos o políticos de coagulación — la historia del marxismo reclama ser construida en su diversidad nacional” (Aricó 2009: 253254).

Podría preguntarme aquí, en efecto, si Aricó era un interlocutor válido para Zea. La pregunta también permite su inversión simétrica: ¿Qué grado de legitimidad podía tener Zea para Aricó? Que Zea lo mencionara aunque más no fuera en una nota a pie indica que el libro de Aricó no había pasado desapercibido. Que tres años después sí llamase a Carlos Real de Azúa pero no a Aricó para participar en un volumen financiado por la UNESCO y que tenía el título de América Latina en sus ideas influye en la sospecha de que Aricó debía quedarse en una nota a pie. En definitiva, lo que Aricó estaba discutiendo era el carácter del "devenir común de América Latina”, como summa de una explicación que él mismo venía a discutir: ese referente de "América Latina” (ya fuera en el reflejo oblicuo de cómo se habían constituido las lecturas de lo que había mirado o no mirado Marx, como uno de los casos más paradigmáticos de la discusión sobre ese objeto). $\underline{19}$

En relación con la validez o legitimidad de la producción de Zea para Aricó, pareciera que construyeron una suerte de "sendas paralelas" o "diálogo de sordos” pero con un sentido específico. Aricó podía conocer la obra del mexicano y adrede ignorarla, hacerla ausente. Porque no parecía haber diálogo posible o confluencia; Zea era uno de los representantes a los que aludía al criticar el uso como si se dijera "tipificado" o "protocolizado" de la acusación de eurocentrismo a Marx (y por ende, a todo el marxismo). A los efectos de una militante integración pro-latinoamericana como lo fue el trabajo de Zea (fuera desde el “pensamiento", fuera desde la "acción”) era necesario contabilizar en el arcón de los recuerdos algún hilo rojo que diera sentido a diferencias tan claramente tangibles como la de los países y poblaciones subcontinentales. En Marx y América Latina, Aricó había tratado justamente de mostrar y explorar una historia no lineal (y que en trabajos posteriores le costaría profundizar, cayendo él mismo en lo que criticaba): menos continua que interpelada por retazos, contradicciones, malentendidos e insistencias. En otras palabras, dar un estatuto explícito a las razones de centrarse en las ausencias y explorar, siempre, sus límites. $\underline{20}$

\section{NOTAS}

1 Como aclara Juan Carlos Portantiero, la primera edición del libro fue en Perú con prólogo del sociólogo Carlos Franco. Luego en México en 1982 y en Buenos Aires en 1987, con una reedición en 2009 (Portantiero 1999). Para una reconstrucción de la factura del libro véase Crespo 2009.

$\underline{2}$ De hecho, así titula el primer capítulo de su libro: "Una realidad soslayada”.

3 Para otro trabajo quedará incorporar también la producción del argentino Oscar Terán, muy cercano a Aricó y cuyo artículo "El primer antiimperialismo latinoamericano", publicado por primera vez en 1980 (y luego en 1986), podría ser leído en estos mismos términos de oposición y crítica a la historia de las ideas á la Zea. Véase Terán 1986. Para un desarrollo que toma en parte esta mirada, véase Pita y Marichal Salinas 2012.

4 Agradezco los atinados comentarios de los/las referí anónimos así como también la lectura atenta de Ricardo Martínez Mazzola. 
$\underline{5}$ En el caso de la CAS, según Yankelevich: "Se trataba de gente con una militancia de izquierda desarrollada, en unos casos, en un peronismo de matriz camporista, pero también había militantes o simpatizantes de organizaciones políticas de cuño marxista o socialista. En su mayoría, todos eran profesionales de clase media” (Yankelevich 2010: 138).

6 José Aricó, carta a Juan Carlos Torre (copia), México df, 26 de diciembre de 1976, en Archivo Aricó, Correspondencia, caja 1, Biblioteca José María Aricó, Universidad Nacional de Córdoba (citado en Crespo 2009: 34).

Z Sobre Aricó, su figura y sus emprendimientos político-culturales véase, entre otros: Burgos 2004; Cortés 2015; Malecki 2013; Ricca 2013 y García 2013; y también véase el dossier dedicado a la revista Pasado y Presente en la revista Prismas (2015). Sobre Aricó y el grupo Pasado y Presente véase Petra 2010a. Allí la autora estudia la trama de la constitución de un grupo específico teniendo muy en cuenta la tradición comunista y la referencia a la universidad para pensar su formación interna. Para un trabajo que define la identidad política de Aricó signada por la "nueva izquierda” véase el ya clásico libro de Terán (1991). Para trabajos que analizan la etapa en el exilio y los tópicos que fueron centrales en las discusiones vinculadas a la derrota de las transformaciones vía la lucha armada, las denuncias de las atrocidades de las dictaduras latinoamericanas y las discusiones sobre la democracia, véase Farías 2015; Gago 2012, Martínez Mazzola 2016 y Reano 2012.

8 Para un trabajo que postula una crítica a esa "historia de las ideas", donde revisa sus fundamentos y los límites que le eran inherentes y por donde avanzaron el sostén de, en principio, la historia conceptual y de la historia de los lenguajes políticos de la Escuela de Cambridge, véase Palti 2012.

9 Véase Kozel 2012: 239-344.

10 Para una breve trayectoria de la vida de Zea, véase Enciclopedia de la filosofía mexicana: http://dcsh.izt.uam.mx/cen doc/cefilibe/images/banners/enciclopedia/Diccionario/Autores/FilosofosMexican os/Zea Leopoldo-Saladino Alberto.pdf (consultado 8/9/2015). Para un trabajo de análisis sobre los motivosideas/fuerza de Zea a lo largo de su trayectoria, véase: Kozel 2012. Para una biografía intelectual véase Tzvi Medin 1992.

11 Aricó terminó La hipótesis de Justo en 1980, aunque lo fue reescribiendo hasta su muerte. El texto obtuvo una mención especial en el Premio de Historia Internacional “José Luis Romero”, cuyo jurado estaba constituido por dos académicos argentinos (Tulio Halperin Donghi y Gregorio Weinberg), uno uruguayo (Juan Carlos Oddone) y uno estadounidense (Richard Morse). Véase, Portantiero 1999: 7. Agradezco a Ricardo Martínez Mazzola recordarme la mención de América Latina, y como “problema”, en este libro.

12 Sobre las propuestas gramscianas vinculadas a la traducibilidad de los lenguajes políticos y el modo en que Aricó las retoma véase, también, los trabajos de Zarowski (2013) y Malecki (2013). Sobre la práctica de la traducción de la cultura italiana y las disputas por esas traducciones, véase Petra 2010b.

13. Véase para otro acercamiento al estudio sobre la conformación de esa historia de las ideas en América Latina: Acosta (2007); Y especialmente: http://www.filosofia.org/ave/001/a348.htm (Última consulta: 1/4/2016).

14 Participaron también Rodolfo Peña, Leandro Konder, Luis Vitale, André Gunder Frank, Antonio Araníbar Quiroga, Jesús Monjaráz Ruiz y Pablo González Casanova.

$\underline{15}$ Para un trabajo acerca de las posiciones de Controversia, véase Farías 2013. 
16 Sobre Real de Azúa y su producción puede consultarse, entre otros: Cotelo 1987; Espeche 2015a y 2015b; Halperin Dongui 1987 y Rocca 2006.

17 Según Andrés Kozel (2012), el período que va de 1952/53 a los años setenta es uno en el que Zea concibe algunas de sus principales ideas-fuerza más desapegadas de las de su maestro, el español José Gaos. Kozel sugiere también que esas mismas ideas-fuerza no pueden concebirse siempre iguales a sí mismas.

18 Y aunque no lo mencionó, no es aleatorio que el análisis de Zea deba leerse a tono con la intervención norteamericana en Guatemala de 1954, como muestrario sintético del devenir de la relación entre esas dos Américas, el lugar del imperialismo allí y el caso guatemalteco como el de la positividad occidental negándose a sí misma. Véase: Kozel 2008: 108.

19 Real de Azúa también discutió el aglutinante latinoamericano, pero un ethos específico que unía lo popular, lo nacional y lo revolucionario fue también el hálito que le permitió establecer mayores parentescos con ciertas propuestas del propio Zea. Véase Espeche (2015a y b).

$\underline{20}$ En un artículo posterior, Aricó pareció desestimar sus propios postulados invocando el par analítico "tradición-modernidad" y un supuesto hilo rojo que podía seguirse a lo largo de la historia de la ciudad de Córdoba en la relación entre cultura y política. En el caso de Real de Azúa, también este par funciona en esos mismos términos, normalizando lo “difuso". Véase, para un análisis en profundidad de ambos temas: García 2013 y Espeche 2015a. También quedará para otro trabajo revisar las objeciones que Álvaro García Linera realiza a Marx y América Latina. Véase, García Linera 2009.

\section{BIBLIOGRAFÍA}

Acosta, Yamandú (2009). "Historia de las ideas e identidad”, en Estudios de filosofía práctica e historia de las ideas, vol. $11 \quad\left(\mathrm{n}^{0}\right.$ 1), pp. 33-43. Recuperado de: http://www.scielo.org.ar/scielo.php? script=sci arttext\&pid=S1851-94902009000100004

Aricó, José María (2009) [1980]. Marx y América Latina, Buenos Aires, Fondo de Cultura Económica.

Aricó, José María (1981). “Presentación”, en Aricó José (comp.), Correspondencia Carlos Marx, Nicolai F. Danielson y Friedrich Engels, México, Siglo XXI.

Aricó, José María (1983). “Marx y América Latina”, en Nueva Sociedad (nº 66), pp. 47-58.

Burgos, Raúl (2004). Los gramscianos argentinos. Cultura y política en la experiencia de Pasado y Presente, Buenos Aires, Siglo XXI.

Cortés, Martín (2010). "La traducción como búsqueda de un marxismo latinoamericano: la trayectoria intelectual de José Aricó”, en A Contra Corriente, vol. 7 ( $\mathrm{n}^{\circ}$ 3), pp. 145-167, doi: www.ncsu.edu/project/acontracorriente

Cortés, Martín (2015). Un nuevo marxismo para América Latina. José Aricó: traductor, editor, intelectual, Buenos Aires, Siglo XXI.

Cotelo, Rubén (1987). Carlos Real de Azúa, de cerca y de lejos, Montevideo, Nuevo Mundo.

Crespo, Horacio (2001). “Celebración del pensamiento de José Aricó”, en Agencia Córdoba Cultura. Recuperado de: http://www.arico.unc.edu.ar/pdf/crespo.pdf 
Crespo, Horacio, (2009). "El marxismo latinoamericano de Aricó. La búsqueda de la autonomía de lo político en la falla de Marx”, en Aricó José (2009), Marx y América Latina (pp. 9-48), Buenos Aires: Siglo XXI.

Espeche, Ximena (2015a). “Carlos Real de Azúa y el problema de las ideas en América Latina”, en Crespo, Horacio, Luis Gerardo Morales Moreno y Mina Alejandra Navarro Trujillo, (coords.), En torno a fronteras intelectuales. Conceptualizaciones, itinerarios y coyunturas institucionales (pp. 317-332), México, Universidad Autónoma del Estado de Morelos / Editorial Itaca.

Espeche, Ximena (2015b, en prensa). La paradoja uruguaya. Intelectuales, latinoamericanismo y nación a mediados de siglo $X X$, Bernal, Universidad Nacional de Quilmes.

Farías, Matías (2013). "Del intelectual revolucionario al intelectual crítico: la relectura de Walsh en Controversia”, en Cuadernos de H Ideas, vol. 7 (n 7), doi: http://perio.unlp.edu.ar/ojs/index.php/cps/index

Farías, Matías (2015). "Un epílogo para los años setenta. Controversiay la crítica a las organizaciones revolucionarias”, en Prislei, Leticia (dir.), Polémicas intelectuales, debates políticos. Las revistas culturales en el siglo XIX (pp. 355-398), Buenos Aires, Editorial de la Facultad de Filosofía y Letras. Colección Libros de Cátedra.

Gago, Verónica (2012). Controversia. Una lengua en el exilio, Buenos Aires, Ediciones Biblioteca Nacional.

García, Diego (2013). “Tradición, modernidad y frontera. Aricó y dos ideas sobre Córdoba”, en Kozel Andrés, Horacio Crespo y Héctor A. Palma (comp.), Heterodoxia y fronteras en América Latina (pp. 55-74), Buenos Aires, Teseo.

García Linera, Álvaro (2009). La potencia plebeya. Acción colectiva e identidades indígenas y populares en Bolivia, Bogotá, Siglo del Hombre Ediciones y CLACSO, doi: http://bibliotecavirtual.clacso.org.ar/ar/libros/coedicion/linera/linera.pdf

Halperin Donghi, Tulio (1987). “Prólogo”, en Real de Azúa, Carlos, Escritos, Montevideo, Arca.

Kozel, Andrés (2008), "La idea de América en el historicismo mexicano. Notas de investigación”, en Anuario, Colegio de México, pp. 95-112.

Kozel, Andrés (2012), “Ethos y desarrollo en Leopoldo Zea”, en Andamios, vol. 9 (n² 20), pp. 13-34.

Malecki, Sebastián (2013). "Difundir, traducir, producir. Aricó y la difusión del marxismo como problemática”, en Revista de Filosofía, pp. 153-177.

Martínez Mazzola, Ricardo, Jimena Montaña y otros (2015). “Dossier: 50 años de Pasado y Presente”, en Prismas. Revista de historia intelectual (nº 18), pp 177-242.

Martínez Mazzola, Ricardo, (2016). "Una ruptura en la tradición. La Ciudad Futura y la construcción de una izquierda democrática, 1986-1991”, en Revista Izquierdas (n² 28), pp. 248-273.

Medin, Tzvi (1992) [1983]. Leopoldo Zea: ideología y filosofía de América Latina, México, Universidad Autónoma de México.

Palti, Elías (2007). "Lugares y no lugares de las ideas en América Latina”, en El tiempo de la política. El siglo XIX reconsiderado (pp.258-308), Buenos Aires, Siglo XXI.

Palti, Elías (2012). “Giro Lingüístico e historia intelectual”, en Giro lingüístico e historia intelectual. Stanley Fish, Dominick Lacapra, Paul Robinow y Richard Rorty (pp. 19-167), Bernal, UNQ. 
Panesi, Jorge (1994). “La traducción en Argentina”, en Voces (n³), pp. 2-7.

Petra, Adriana (2010a). "En la zona de contacto: Pasado y Presente y la formación de un grupo cultural”, en Agüero Ana Clarisa y Diego García (Eds.), Culturas interiores. Córdoba en la geografía nacional e internacional de la cultura (pp. 213-240), La Plata, Ediciones Al Margen.

Petra, Adriana (2010b). "El momento peninsular. La cultura italiana de posguerra y los intelectuales comunistas argentinos”, en Revista Izquierdas $\left(\mathrm{n}^{\circ} 8\right)$.

Pita González, Alexandra y Carlos Marichal Salinas (coords.) (2012). Pensar el antiimperialismo. Ensayos de historia intelectual latinoamericana, 1900-1930, México/Colima, Colmex/Universidad de Colima.

Portantiero, Juan Carlos (1999). “Prólogo”, en Aricó José M., La hipótesis de Justo (pp. 7-12), Buenos Aires, Sudamericana.

Real de Azúa, Carlos (1975). Historia visible e historia esotérica. Personajes y claves del debate latinoamericano, Montevideo, Calicanto-Arca.

Reano, Ariana (2012). “Controversia y La Ciudad Futura: democracia y socialismo en debate”, en Revista Mexicana de Sociología, vol. $74 \quad\left(n^{\circ} \quad 3\right)$ 3) $\begin{array}{llll}\text { pp. 487-511. Recuperado de: }\end{array}$ http://www.scielo.org.mx/pdf/rms/v74n3/v74n3a5.pdf

Ricca, Guillermo (2013). “Marx después de Marx: eurocentrismo, crítica y política en José M. Aricó”, en Utopía y Praxis Latinoamericana (nº 61), pp. 71-87.

Rocca, Pablo (2006). "El caso Real: alternativas críticas americanas”, en Prismas. Revista de historia intelectual $\left(\mathrm{n}^{\circ} 10\right)$, pp. 37-54.

Tarcus, Horacio (2015). "Una invitación a la historia intelectual. Palabras de apertura del II Congreso de Historia Intelectual de América Latina”, en Revista Pléyade ( ${ }^{\circ}$ 15), pp. 9-25. Recuperado de: https://www.academia.edu/15397381/Una invitaci

\%C3\%B3n a la historia intelectual. Palabras de apertura del II Congreso de Historia Intelectual de Am\%C3\%A9rica Latina

Terán, Oscar (1981). “El primer antiimperialismo argentino”. Punto de Vista, año IV, julio-octubre de 1981, pp. 3-10.

Terán, Oscar (1991). Nuestros años sesenta. La formación de la nueva izquierda intelectual en Argentina (1956-1966), Buenos Aires, Puntosur.

Yankelevich, Pablo (2010). Ráfagas de un exilio. Argentinos en México, 1974-1983, Buenos Aires, Fondo de Cultura Económica.

Zarowsky, Mariano (2013). “Gramsci y la traducción. Génesis y alcances de una metáfora”. Prismas. Revista de historia intelectual, vol. 17 ( ${ }^{\circ}$ 1), pp. 49-66.

Zea, Leopoldo (1983), "Visión de Marx sobre América Latina”, en Revista Nueva Sociedad (nº 66), pp. 5966. 